\title{
INOVAÇÕES E TENDÊNCIAS APLICADAS NAS TECNOLOGIAS DE INFORMAÇÃO E COMUNICAÇÃO NA GESTÃo DA SAÚDE
}

\section{RESUMO}

Os diferentes modelos de negócios na área da saúde estão possibilitando que se desenvolvam os mais variados tipos de estratégias de negócios, oferecendo cada vez mais versatilidade e funcionalidade, principalmente utilizando a ferramenta internet. As empresas estão realizando transações de forma mais eficiente e eficaz, e este fato vem causando um processo crescente de obsolescência dos negócios consolidados no setor da saúde. Portanto, o objetivo deste trabalho é apresentar uma discussão sobre as principais tendências de Tecnologia da Informação que estão trazendo benefícios diretos e indiretos para a Gestão da Saúde. Esta pesquisa caracterizou-se por ser exploratória com caráter analítico em fontes secundárias. Dentre os resultados foi observado que o problema com o gerenciamento da informação tem sido ainda mais dificultado devido a um exponencial aumento na quantidade de dados a serem gerenciados, no número de profissionais, que controlam os processos e nas demandas para acesso em tempo real. A tecnologia pode agir como legitimadora do ato profissional da saúde e da instituição que a adota, sendo utilizada como critério de avaliação de qualidade dos seus serviços prestados. Nesse sentido, faz-se necessário um posicionamento estratégico das organizações da área da saúde para o tratamento dos recursos informacionais, bem como, a escolha de um conjunto de ferramentas de Tecnologia da Informação capaz de trazer os benefícios esperados para estas organizações.

Palavras-chave: Tendências; Inovação; Tecnologia da Informação; Gestão da Saúde.

\section{INNOVATIONS AND TRENDS IN APPLIED INFORMATION AND COMMUNICATION TECHNOLOGIES IN HEALTH MANAGEMENT}

\begin{abstract}
The different business models in health are enabling them to develop all kinds of business strategies, offering more versatility and functionality, mostly using the internet tool. Companies are making transactions more efficiently and effectively, and this fact has caused an increasing obsolescence of the consolidated business in the health sector. Therefore, the objective of this study is to present the new trends emerging information technologies that are bringing direct and indirect benefits for the Management of Health. This research was characterized by analytical character to be exploratory in secondary sources. Among the main results was observed with the problem of information management has been further hampered due to an exponential increase in the amount of data to be managed, the number of professionals who control the processes and demands for real-time access. Technology can act as legitimizing the act of professional health and the institution adopts, being used as a criterion for evaluating the quality of their services. In this sense, it is necessary a strategic positioning of health care organizations for the treatment of information resources, as well as the choice of an Information Technology tool kit able to bring the expected benefits to these organizations.
\end{abstract}

Keywords: Trends; Innovation; Information Technology; Health Management.

Luis Hernan Contreras Pinochet ${ }^{1}$

Aline de Souza Lopes ${ }^{2}$ Jheniffer Sanches Silva ${ }^{3}$

\footnotetext{
${ }^{1}$ Doutor em Administração de Empresas pela Fundação Getúlio Vargas - FGV/SP. Professor da Universidade Federal de São Paulo - UNIFESP. Brasil. E-mail: luis.hernan@unifesp.br

${ }^{2}$ Centro Universitário São Camilo - SP. Brasil. E-mail: aline.souza.lopes@ hotmail.com

${ }^{3}$ Centro Universitário São Camilo - SP. Brasil. E-mail: jheniffersanches@ hotmail.com
} 


\section{INTRODUÇÃO}

Nas últimas décadas temos presenciado um processo de transformação e de inovação tecnológica sem precedentes na área da saúde. Como consequência, a diferenciação dos serviços da saúde em seus subsetores públicos e de mercado é aprofundada. Com isso, segundo Gadelha (2003; 2006) o setor da saúde representa um espaço simultâneo de inovação e acumulação de capital sendo o mercado, o espaço concreto onde os capitais se defrontam.

A era da informação não deixou à margem a área da saúde. De fato, a tecnologia ultrapassou o processamento-padrão de dados para funções administrativas comuns em todas as organizações, tais como recursos humanos, folhas de pagamento, sistemas de contabilidade, entre outros, e agora desempenha um papel fundamental tanto no cuidado ao paciente, na interpretação do eletrocardiograma, como em escalas de trabalho, prescrição, relatório de resultados e sistemas de prevenção.

Segundo Hannan, Ball, e Edwards (2009) começamos a presenciar o advento de registros eletrônicos da saúde em muitos países. Além disso, os sistemas de informação estão sendo amplamente usados no apoio à saúde da população e nas atividades da saúde pública relacionados a prevenção e promoção da saúde, controle de doenças, vigilância e monitoramento.

Reduzir custos e aumentar a eficiência é uma busca constante de qualquer empresa, mas no caso dos hospitais essa combinação pode ser uma questão de sobrevivência. A situação do sistema da saúde brasileiro exige cuidados especiais. Com o crescimento dos gastos em saúde, resultado da adoção de alta tecnologia para diagnóstico, e o alto índice de desperdício, o segmento enfrenta dificuldades para equilibrar as contas.

Seja na área pública, reconhecidamente carente, ou na privada, em que as operadoras de planos da saúde reclamam das perdas contabilizadas, não há dúvidas de que é preciso rever processos e investir em tecnologias capazes de aumentar o controle e melhorar a qualidade da assistência.

Nos ambientes hospitalares é frequente encontrar centenas de aplicações diferentes e que, além disso, os softwares de informatização hospitalar sejam geralmente complexos, de alto custo, e de difícil desenvolvimento e implementação. Assim, faz-se necessário um posicionamento estratégico das organizações da área da saúde para o tratamento dos recursos informacionais, bem como, a escolha de uma ferramenta de Tecnologia da Informação e Comunicação - TIC, capaz de trazer os benefícios esperados para estas organizações.

Portanto, o objetivo deste trabalho é apresentar uma discussão sobre as novas tendências de
Tecnologia da Informação emergentes que estão trazendo benefícios diretos e indiretos para a Gestão da Saúde. O artigo está organizado nas seguintes seções: introdução; metodologia; referencial teórico; evolução das tecnologias de informação e comunicação em saúde; e finaliza com a discussão das TICs em saúde descritas no estudo.

\section{METODOLOGIA}

A pesquisa ancora-se na metodologia do tipo exploratória, uma vez que tem como objetivo o aprofundamento sobre o tema escolhido (Gil, 2010). A coleta de dados foi realizada em diferentes fontes de bases de dados, com o apoio de artigos e revistas nacionais e internacionais, monografias, dissertações, teses, internet, e livros especializados na área da gestão da saúde. Portanto, caracterizou-se como uma pesquisa bibliográfica com caráter analítico.

Esta pesquisa tem a finalidade de proporcionar maior compreensão do fenômeno investigado, permitindo assim, que se delineie de forma mais precisa o problema a ser discutido, através de informações extraídas e da comunicação escrita.

As fontes secundárias, conforme Andrade (2001) referem-se a determinadas fontes que são constituídas pela literatura originada de determinadas fontes primárias e constituem-se em fontes de pesquisa bibliográfica.

Os dados apresentados na pesquisa são de caráter qualitativo, pois as tecnologias que foram selecionadas e analisadas para esta pesquisa contemplam fenômenos que envolvem as organizações da saúde.

\section{REFERENCIAL TEÓRICO}

\subsection{A Tecnologia da Informação e Comunicação como Recurso Estratégico}

Segundo Spinola e Pessôa (1997), a informação é uma ferramenta poderosa para uma organização pois, por meio dela, pode-se ter o domínio dos diversos parâmetros que regem a sua dinâmica. Nos sistemas empresariais, a informação é reconhecida como o recurso mais importante para a tomada de decisões, sendo necessário haver uma malha de informações abrangendo diversos aspectos técnico-científicos, administrativos, mercadológicos, econômicos, legais, ambientais e políticos.

Segundo McGee e Prusak (1994), as informações constituem um importante insumo estratégico, capaz de influenciar o negócio da empresa, tornando-se cada vez mais a base para a competição.

A informação representa um recurso de vital 
importância para o sucesso das organizações, pois, uma empresa será mais competitiva quanto mais se destacar na exploração e no uso da informação para geração de conhecimento e souber aplicá-lo para desenvolver novas oportunidades de negócios (Sweeney, 1989).

Porter (1991) destaca que a essência da formulação de uma estratégia está em relacionar a empresa ao seu ambiente. Oliveira (1995) complementa definindo estratégia como um caminho, maneira ou ação, estabelecida e adequada para alcançar os resultados da empresa, representados por seus objetivos, desafios e metas. Moura (1999) relaciona a estratégia com o conjunto de decisões que são tomadas visando definir a direção a ser seguida para se posicionar frente ao ambiente.

Campos e Teixeira (2004) verificaram que entre os recursos tecnológicos, a Tecnologia da Informação e Comunicação - TIC (complexo tecnológico que envolve computadores, software, redes de comunicação eletrônica públicas e privadas, rede digital de serviços de telecomunicações, protocolos de transmissão de dados e outros serviços) (Marcovitch, 1996) - tem sido apontada como importante fator para potencializar o desenvolvimento dos processos produtivos e da gestão das organizações (Santos; Vieira, 1998).

Várias pesquisas sobre a relação entre tecnologia e organizações têm sido empreendidas desde a década de 1960 (Gerwin, 1981 apud Roberts; Grabowiski, 1996). A partir delas, muitas questões foram levantadas. Tapscott e Caston (1995) ressaltam que são necessárias mudanças nos processos organizacionais para que a tecnologia implantada surta efeitos positivos em ambientes reestruturados para um novo modo de atuação.

Segundo Oliveira e Spinola (2005) a Tecnologia da Informação e Comunicação tem sido um dos maiores impulsionadores deste processo de mudança. Desde a informatização das empresas integrando suas áreas internas, passando por redes de clientes e fornecedores, até as tecnologias de ponta como utilização de equipamentos sem fio, telemedicina, prontuário eletrônico, entre outros, vem acelerando cada vez mais este setor de uma forma nunca observada anteriormente.

A hipótese para este fenômeno é de que a tecnologia da informação, ora oferece maior eficiência (Laurindo, 2002) as empresas e portanto, reduz custos, ora possibilita maior eficácia, o que gera maior valor ou novas formas de valor aos clientes em geral, e resulta na entrada de empresas em novos mercados e ao mesmo tempo contribui com a sustentabilidade das mesmas.

\subsection{A Questão da Informatização na Gestão Hospitalar}

Com a expansão e a evolução constante da TIC, os gestores voltados à gestão hospitalar, tiveram a percepção de que a tecnologia é fundamental para a tomada de decisões gerenciais de forma objetiva e rápida.

Nota-se com essa percepção, uma das possibilidades de melhoria das rotinas de uma gestão hospitalar, como, redução de custos, pois uma gestão direcionada pela TIC permite o aumento de controle de situações decisivas tanto para a sobrevivência de pacientes quanto para a saúde econômico-financeira da própria instituição.

Na visão de Santos (1998) a informática é mais uma das ferramentas que os hospitais terão para reunir a informação necessária para cumprir o seu trabalho de maneira eficiente.

Para que os hospitais mantenham de forma ascendente suas atividades e serviços prestados, houve a importante busca da atualização do setor tecnológico, garantindo assim, maior desenvolvimento e melhor qualidade no atendimento ao paciente.

E na visão de Mañas (2002), trabalhando a informação de forma correta, a empresa consegue direcionar seus colaboradores para atender da melhor maneira possível ao cliente.

Tratar as informações geradas nas instituições da saúde tem sido um grande desafio. Mas, ao mesmo tempo, uma importante oportunidade comercial para o mercado de TIC. O desafio detectado por este mercado é interpretar a necessidade destas instituições, com alta complexidade e transformar esta variável em recursos tecnológicos que ajudem a melhoria do atendimento ao paciente. Aqui se atribui a necessidade do uso de recursos tecnológicos inteligentes e de sistemas integrados para a gestão da saúde.

A chegada da TIC dentro das instituições hospitalares causou de fato uma grande revolução tecnológica de processos e procedimentos administrativos e assistenciais. Oferecer um atendimento qualificado ao paciente, ter maior precisão no diagnóstico, aumentando sua expectativa de vida e administrar as informações geradas dentro das instituições, são sem dúvida, fatores motivadores que movimentam a TIC dentro do setor da saúde.

Na visão de Serafim (2005), o uso da TIC por gestores da saúde tem se tornado cada vez mais importante. Este instrumento serve como fonte de informação sobre os indicadores do hospital, fornecendo dados importantes sobre a instituição e apoiando o processo decisório e estratégico da gestão administrativa.

Todo o processo de implantação da TIC dentro dos hospitais ocorre ainda paulatinamente, pois relacionar a tecnologia com o ato do cuidado e assistência à saúde do paciente, não é uma tarefa fácil para os desenvolvedores das soluções e equipamentos 
da TIC, tanto em diminuir o índice de erro na solução oferecida, quanto a valores para adquirir, implantar e manter estas soluções.

Ainda na implantação das soluções de TIC, é importante atentar-se ao gerenciamento da integração entre os profissionais da saúde e os recursos tecnológicos ali expostos. Pois, existe o fato da adaptação deste profissional com o recurso a ele apresentado. Neste cenário tecnológico, o profissional, pode ou não apresentar interesse na aprendizagem e no conhecimento das ferramentas que lhe beneficiarão em suas atividades.

Hospitais são organizações complexas e com os mais diversos processos e procedimentos nos setores administrativos e de assistência. Estes ambientes precisam estar integrados para maximizar a eficiência e precisão no atendimento de seus clientes.

Dia após dia, percebe-se o quanto a TIC, através de Sistemas de Informação Integrados, evolui dentro das instituições hospitalares, tornando-se rica e satisfatória, com o propósito em apoiar as equipes multiprofissionais, oferecer agilidade nos processos, aumentar o desempenho das atividades prestadas, gerar conforto ao paciente em relação à precisão de diagnósticos empenhando sua expectativa em relação a sua saúde.

\subsection{Automação da Gestão Hospitalar}

A automação da Gestão Hospitalar de processos e serviços é uma prática o qual possibilita uma melhora no gerenciamento de informações, como por exemplo, no controle de medicamentos ou as chamadas farmácias hospitalares.

Logo, um hospital que tem esse controle de estoque de materiais e medicamentos informatizado ou automatizado, pode alcançar redução média de custos entre $15 \%$ e $20 \%$, sendo que alguns chegam a $30 \%$ em redução de custos, segundo Santos (1998).

Enfatiza-se a questão da redução de custos através de processos informatizados na Gestão Hospitalar, como por exemplo, no controle de estoque de materiais e medicamentos. Com essa atitude, concentra-se em redução do re-trabalho, redução ou eliminação de roubos de materiais/medicamentos e redução de custos do setor de compras.

Chiasson e Davidson (2004) observam que a área da saúde, especificamente, a hospitalar, oferece oportunidades para o desenvolvimento $\mathrm{e}$ aprimoramento de teorias de sistemas de informação em razão do seu contexto único e peculiar, representado por usuários que devem satisfazer requisitos profissionais exigentes e para os quais a liberdade de ação em relação aos processos burocrátios pode ser fundamental.

O sistema de informação elaborado com vista à segurança do paciente tem o objetivo de evitar a ocorrência de erros e indentificar aqueles que realmente ocorrem de forma a minimizar seus impactos na gestão hospitalar. A American Society of Hospital Pharmacistis (ASHP) destaca conforme Cassiani et al. (2005) que para evitar erros na medição estão: informatização do sistema (prescrição, dispensação, distribuição do medicamento); uso do código de barras nos processos de medicação e na identificação do paciente.

\subsection{Automação de Fluxos e Processos Hospitalares}

A automação de fluxos e processos hospitalares significa fornecer à organização a informação segura para futura utilização, através de sistemas de informação. Todo sistema de informação necessita ser alimentado de dados que são processados e disponibilizados para diversos usuários e finalidades, como médicos, enfermeiros, administradores, contabilistas, entre outros.

A automação também permite, por exemplo, através da utilização de código de barras um gerenciamento mais seguro da qualidade da informação que está alimentando o sistema da empresa. Suas principais características são a velocidade e precisão na entrada de dados que informam o sistema e a eliminação de erros e omissões no preenchimento de guias e controles.

Barros et al. (2013) observaram o modelo de gestão do fluxo de regulação de pacientes com o uso de ferramentas de Business Process Management (BPM) no maior complexo hospitalar da América Latina. Isto permitiu o mapeamento de tempo e a obtenção de indicadores, sem afetar a operação, evitando customizações nos diversos sistemas legados (sistemas antigos e de difícil integração), o que poderia impactar na efetividade da solução. Detacou-se o BPM como solução tecnológica que permitiu maior controle dos processos, e rastreabilidade, além de não interferir nas operações, na medida que foram sendo substituidas as planilhas do excel por formulários eletrônicos integrados.

\section{EVOLUÇÃ̃ DAS TECNOLOGIAS DE INFORMAÇÃO E COMUNICAÇÃO EM SAÚDE}

O gerenciamento da informação em setores hospitalares e áreas afins é um componente essencial no processo de prestação de cuidados ao paciente. $\mathrm{O}$ problema com o gerenciamento da informação tem sido ainda mais dificultado devido a um exponencial aumento na quantidade de dados a serem gerenciados, no número de profissionais, que controlam os processos e nas demandas para acesso em tempo real. $\mathrm{O}$ custo para lidar com a informação nos hospitais também tem representado o principal fator para o uso de computadores, na tentativa de fornecer mais dados 
com menor custo.

Barra et al. (2006) identificaram que as transformações tecnológicas no setor da saúde se encontram cada vez mais rápidas e a cada momento surgem novas técnicas diferentes e aparatos mais modernos no mercado com novas inovações. A descoberta do Raio X final do século XIX, e sua aplicação com fins de diagnósticos no início do século XX constituiu um marco importante na história da medicina, e consequentemente, na tecnologia da saúde. O sucesso do emprego do Raio X levou os profissionais à busca de outros métodos diagnósticos por imagens, sendo presenciados nessa geração o aparecimento da ultrassonografia, da tomografia computadorizada e da ressonância nuclear magnética segundo Dias et al. (1996).

\subsection{Classificação dos Sistemas de Informação na Área da Saúde}

Os sistemas de informação em uso na área da saúde podem ser genericamente classificados em três tipos segundo Hannan, Ball, e Edwards (2009):

- O primeiro é composto de sistemas limitados quanto ao objetivo e ao escopo. O mais comum é o sistema isolado (stand-alone) direcionado a uma área específica de aplicação. Exemplos são aqueles dedicados para calcular a carga horária dos enfermeiros, que vários hospitais possuem. Nos hospitais, os sistemas incluídos nessse grupo são direcionados a laboratórios, controle financeiro, radiologia, eletrocardiografia, controle de funções pulmonares, sistema de farmácia e nutrição. Na área da saúde pública, os sistemas de imunização podem ser considerados como outro bom exemplo dessa categoria.

- O segundo tipo é composto de sistema de informação hospitalar, que consiste de uma rede de comunicação, um componente clínico e um componente administrativo e financeiro. $\mathrm{O}$ componente geral de comunicação integra essas três grandes partes em um sistema de informação mais coeso. Um sistema típico de informação hospitalar nessa categoria possibilita ter terminais de computadores em cada posto de enfermagem, assim como terminais que estão ou podem ser acessados em cada área do hospital. Os terminais são unidos por meio de um ou mais computadores de grande porte que podem estar no local ou fora dele. Em geral, são direcionados para a prestação de cuidado intensivo e organizados de acordo com as funções dos departamentos.
- O terceiro, os sistemas corporativos de informação em saúde estão em expansão nos ambientes da saúde. Tais sistemas capturam e armazenam informações mais completas, provenientes da assistência à saúde contínua realizada por diferentes organizações, usando um modelo integrado de prestação de serviços. Esses registros são capturados e depositados em diversos tipos de mídia, incluindo som, imagem, animação e impressão. Os registros podem ser armazenados de modo central, em um formato total e abstrato, usando a abordagem dos data warehouse - sistemas que realizam tratamento de dados armazenados. Como alternativa, esses registros podem ser fisicamente armazenados no ponto de captura e ligados a um registro virtual, que será unido somente quando for solicitado para atender à demanda dos cuidados. Esses sistemas são caracterizados por focar o paciente que está recebendo o cuidado, em diversos setores (por exemplo, ambulatório, unidade de tratamento intensivo, internação de longa permanência), com uma estrutura comum e organizada.

Um pressuposto implícito no desenvolvimento de um Sistema de Informação Hospitalar - SIH é a habilidade de fornecer o dado completo, exato e no momento adequado para que a pessoa que esteja prestando a assistência possa desempenhar sua tarefa com maior qualidade e com melhor razão custo/benefício. O fundamento de tal pressuposto é dado pela simples observação: esses sistemas eliminam as redundâncias nos exames e a necessidade de estabelecer mais de uma vez diagnósticos, fornecendo maior ciência sobre os medicamentos que o paciente está usando e uma melhor comunicação entre todos os profissionais envolvidos com o cuidado ao paciente.

De forma gradual os SIHs evoluíram com a rede de comunicação que unia terminais e os aparelhos de controle, que emitiam informação nos pontos-chave de prestação de cuidados ao paciente e nas áreas de serviço a uma unidade central de processamento que coordenava todas as atividades essenciais de atendimento ao paciente.

A diferença entre os sistemas que eram enquadrados nessa categoria não é a forma de comunicação, mas a complexidade da integração de suas funções de aplicação. Certos sistemas possuem condições mais sofisticadas do que outros para validar, verificar, editar, formatar e documentar. Alguns respondem mais rápido e oferecem melhor qualidade de visualização. Essas variações são diferenças a serem consideradas nos aspectos de apresentação e 
comunicação do sistema. Outros fornecem capacidade de integração mais complexa na estrutura da aplicação e na retenção de dados.

Hannan, Ball, e Edwards (2009) verificaram que um exemplo disso é a integração total de informação que existe, proveniente de um laboratório, da radiologia, da farmácia, e dos registros médicos, que, por sua vez, interagem com o serviço de enfermagem, comunicando desde a prescrição até os resultados de exames.

O fato é que os avanços tecnológicos em especial em TIC, nos mais diversos setores, exigem um alto investimento, têm um custo operacional e de manutenção altos e tornam-se obsoletos rapidamente. É por isso que uma gestão competente, que compreenda a dinâmica deste cenário e que tome decisões assertivas alinhadas às estratégias de curto e longo prazo da organização, é fundamental.

Neste cenário a gestão da TIC nas organizações hospitalares tem papel determinante, uma vez que a TIC é hoje o foco das maiores inovações, permeia toda a organização e vai além, estabelecendo uma nova dinâmica de relacionamento com todos os participantes deste mercado.

Muitas organizações da área da saúde como hospitais, laboratórios, operadoras de plano da saúde, entre outras, buscam pacotes de softwares para seus negócios com o objetivo de permitir suas empresas automatizar e integrar a maioria de seus processos de negócios, compartilhar práticas e dados comuns através de toda a empresa e produzir e acessar informações em tempo real.

Este tipo de sistema integrado de gestão é denominado ERP (Enterprise Resource Planning) e caracteriza-se basicamente por integrar diferentes áreas da organização em uma única aplicação, ou seja, um único sistema com a visão de processos de negócio, e não mais a visão departamentalizada que a precedeu.

Tenório (2007) identificou que os ERP contêm diferentes módulos por área funcional ou processo, trabalhando de forma integrada e geralmente em tempo real. Os sistemas integrados de gestão, expressão maior do uso da TIC, compõem um fenômeno recente no panorama empresarial. Eles podem ser aplicados praticamente a qualquer empresa, devido a sua grande adaptabilidade.
A adaptabilidade dos ERP a diferentes tipos de empresas advém dos processos de configurações (customização) do sistema - diversas tabelas que associam processos a procedimentos (rotinas de programas). Conforme esses processos e procedimentos requeridos pela empresa constem dessas tabelas, o ERP terá maior ou menor nível de adesão à forma de ser e trabalhar da empresa. Quanto maior for a adesão de uma solução de ERP, menores serão as adaptações a serem feitas durante o processo de customização e menores serão o tempo e o custo de implementação. Essas adaptações são feitas através de programas de computador que, após executarem os procedimentos, disponibilizam os dados para que o ERP os processe.

Entre os principais fatores motivadores que levam as organizações da área da saúde a implantar um sistema de informação de ERP destacam-se: o estratégico, a legislação e a tecnologia. O primeiro está relacionado à melhoria de competitividade $\mathrm{e}$ lucratividade, enquanto o segundo refere-se às exigências legais que a organização deve cumprir e que não estão sendo contempladas pelas aplicações atuais. Já o fator tecnologia está relacionado ao obsoletismo - tecnologias ultrapassadas tornam-se economicamente inviáveis de serem mantidas.

Os benefícios prometidos com a implantação do ERP são bastante tentadores, embora nem sempre a realidade seja tão agradável. Esses benefícios, em geral, representam maior possibilidade de controle dos processos, atualização tecnológica, redução dos custos de informática, retorno de investimento e acesso a informações de qualidade em tempo real para tomada de decisão (Souza; Zwicker, 2000).

Raitoharju e Laine (2006) consideram que a aceitação de sistemas de informação no contexto da saúde é um dos fatores críticos de sucesso para a obtenção dos benefícios esperados com os investimentos efetuados com esse tipo de tecnologia.

No quadro 01 são apresentadas de forma cronológica algumas das grandes mudanças na TIC na área da saúde que estão impulsionando os hospitais a se tornarem unidades de negócios. Observa-se que os sistemas de gerenciamento integrado das informações administrativas e clínicas, como ERPs, HIS , BI, PACS, tornaram-se ferramentas fundamentais para as instituições da saúde. 


\begin{tabular}{|c|c|c|}
\hline ANO & TECNOLOGIA & DESCRIÇÃO \\
\hline 1992 & HIS (Hospital Information System) & $\begin{array}{l}\text { Primeiros ERPs clínicos começam a ser utilizados no } \\
\text { Brasil. }\end{array}$ \\
\hline 1998 & Prescrição Eletrônica do Médico & $\begin{array}{l}\text { Profissionais da saúde começam a prescrever } \\
\text { informações do paciente por meio eletrônico. }\end{array}$ \\
\hline 2000 & Portal de Informações Gerenciais & $\left(2^{\mathrm{a}}\right.$ fase do HIS $)$ \\
\hline 2002 & BI - Business Inteligence & $\begin{array}{l}\text { Hospitais começam a utilizar informações geradas pelos } \\
\text { ERPs de forma estratégica para o negócio. }\end{array}$ \\
\hline 2003 & $\begin{array}{l}\text { PACS - Picture Archiving and } \\
\text { Communication Systems }\end{array}$ & $\begin{array}{l}\text { Instituições armazenam e gerenciam seus exames de } \\
\text { diagnóstico por imagem de forma eletrônica. }\end{array}$ \\
\hline 2007 & BSC - Balanced Score Card & Hospitais adotam ferramentas para medir desempenho. \\
\hline 2007 & Farmácia sem papel & $\begin{array}{l}\text { ERPs são integrados ao setor de farmácia com objetivo } \\
\text { de otimizar processos e aumentar segurança na } \\
\text { dispensação de medicamentos. }\end{array}$ \\
\hline 2008 & Mobilidade & $\begin{array}{l}\text { Uso de tecnologia móvel dentro e fora das instituições } \\
\text { da saúde. }\end{array}$ \\
\hline 2009 & Certificação Digital & $\begin{array}{l}\text { Método traz mais segurança para a prescrição } \\
\text { eletrônica. }\end{array}$ \\
\hline 2010 & Tecnologia sem papel & $\begin{array}{l}\text { Automação de processos reduz custo operacional e } \\
\text { melhora o desempenho das equipes assistenciais e } \\
\text { administrativas dos hospitais. }\end{array}$ \\
\hline 2011 & $3^{\mathrm{a}}$ fase do HIS & $\begin{array}{l}\text { Integração de informação entre redes de hospitais, Data } \\
\text { Center, EaD. }\end{array}$ \\
\hline
\end{tabular}

Quadro 1 - Retrospectiva histórica das principais marcos tecnológicos na saúde Fonte: Elaborado pelos autores.

\subsection{Tecnologias Emergentes na Saúde}

A utilização da Tecnologia da Informação e Comunicação (TIC) na saúde cresce a cada dia e portanto, inúmeras são as possibilidades, os recursos e os benefícios que a informática pode trazer para a área e, especialmente para os profissionais da saúde. A seguir são apresentadas algumas tecnologias emergentes que estão contribuindo para a área da saúde (Siqueira, 2007):

\section{Prontuário eletrônico do paciente (PEP): é um registro computadorizado de paciente, cuja informação é mantida eletronicamente sobre o status e o cuidado da saúde do indivíduo durante sua permanência dentro do ambiente hospitalar. Na visão de Sabatini (2002), este registro pode ser percebido como um instrumento ativo, uma central de serviços de informação, um promotor da saúde e de prevenção de problemas, e um educador de pacientes e divulgador de informações confiáveis sobre medicina e saúde. Segundo Siqueira (2007) o prontuário do paciente é o modo principal da atenção médica em todas as organizações da saúde. O registro é constituído}

\footnotetext{
${ }^{4}$ Cartilha sobre Prontuário Eletrônico - a certificação de sistemas de registro eletrônico da saúde. Segurança e confidencialidade para a informação do paciente. Fevereiro
}

de dados para identificação, dados sócioeconômicos, dados dos profissionais, dados radiológicos, e dados laboratoriais, constituindo-se na história do paciente, sendo, portanto, indispensável, para a comunicação entre os profissionais e o paciente, a continuidade, a segurança, a eficácia e a qualidade de seu tratamento (Pinto, 2006). No Brasil o prontuário eletrônico do paciente é a principal ferramenta de TIC que o médico precisa lidar nas suas atividades (consultório, centro de diagnóstico, ou hospital). É fundamental que esta ferramenta tecnológica possibilite o registro da história clínica e exame físico, bem como na solicitação de exames e prescrição. Outro conceito importante é o Registro Eletrônico da Saúde (RES) que permite $o$ armazenamento e o compartilhamento seguro das informações de um paciente. O Conselho Federal de Medicina (CFM) e a Sociedade Brasileira de Informática em Saúde (SBIS) estabeleceram um convênio de cooperação técnico-científica que está em vigência desde $2002^{4}$. Este convênio possibilitou a criação de um processo de Certificação de Sistemas de Registro

de 2012. Conselho Federal de Medicina e SBIS (Sociedade Brasileira de Informática em Saúde). 
Eletrônico em Saúde, com o estabelecimento dos requisitos obrigatórios e, acompanhando a legislação federal para documento eletrônico, isto reforçou a obrigatoriedade do uso de certificação digital (assinatura digital) para a validade ética e jurídica de um PEP/RES. Isto tornou-se um marco regulatório importante que foi publicado na Resolução CFM $\mathrm{N}^{\mathrm{o}}$ $1821 / 2007$.

BI (Business Intelligence): solução que apóia praticamente todos os processos da empresa. As informações gerenciais e os indicadores necessários para a tomada de decisão saem de sistemas que integram a solução fazendo o alinhamento com o negócio. O BI é conhecido como um conjunto de aplicações projetadas para organizar e estruturar dados de transação de uma empresa de forma que possam ser analisados a fim de beneficiar as operações e o suporte às decisões da empresa.

Cartões inteligentes (smart cards): outra maneira de implementar o PEP é o uso dos cartões inteligentes, usados para armazenar informações demográficas e clínicas sobre os pacientes de forma mais descentralizada. Eles podem ser de três tipos: magnéticos, com chip (circuitos integrados) ou ópticos. Os cartões de menor capacidade contêm um conjunto mínimo de dados sobre o paciente, como pessoais e civis, diagnósticos principais, alergias, tipo sanguíneo, plano da saúde, entre outros.

Tecnologias sem fio e computação móvel: esta tecnologia abre caminho para o surgimento de milhares de redes internas em hospitais. Acompanhando esta evolução tecnológica, há muitas aplicações para as plataformas móveis que vem surgindo na área da saúde. Terminais portáveis dão acesso ao Sistema de informação Hospitalar, de modo que os médicos e enfermeiros possam acessar o PEP de qualquer ponto do hospital, introduzir dados, preencher pedidos e prescrições, e assim por diante. Audy e Caye (2013) observaram que o avanço do uso de tablets e smartphones no mercado brasileiro e a adoção destes dispositivos pessoais no ambiente de trabalho (consumerização) no qual os profissionais da saúde tiveram acesso às informações clínicas de seus pacientes que estão armazenadas na solução de prontuários eletrônicos, através de uma rede sem fio. Além da consulta a diagnósticos, prescrição vigente, resultados e laudos de exames é permitido o registro da evolução, sinais vitais e monitorizações do paciente (seguindo os mesmos princípios éticos adotados no prontuário do paciente usado em computadores). Incluso nas tecnologias sem fio, em uma combinação com rede wireless e um smartphone surge o sistema de gerenciamento de sono, que detecta ondas cerebrais para determinar quando os usuários estão em sono profundo e usa as informações para acordá-los no momento ideal, além de realizar uma análise critíca dos dados repassando aos usuários uma classificação de como foi o sono em uma determinada noite, através de gráficos com padrões de sono, enviadas automaticamente através de uma conexão bluetooth.

Abaixo segue imagem do produto original, formado por um relógio que coleta dados em um cartão de memória, que ao ser conectado realiza o upload para um painel online, e produto adaptado para smarphones. (Figura 01).

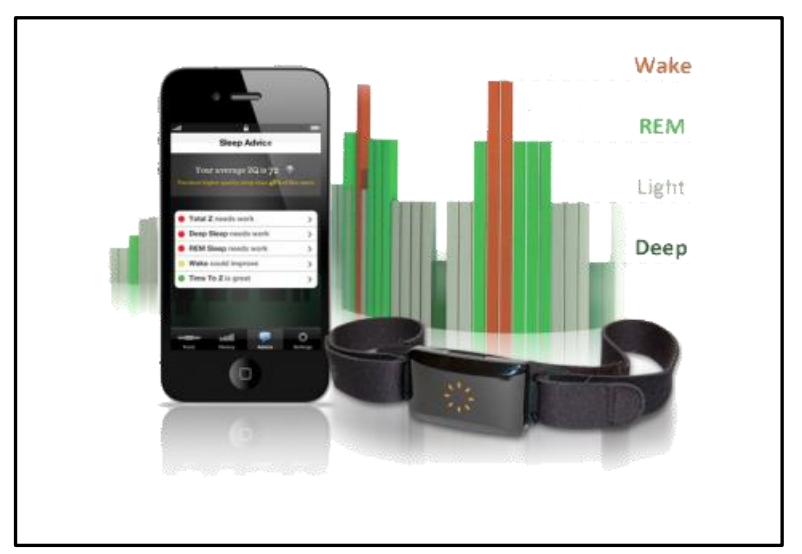

Figura 1 - Aparelhos de Gerenciamento do Sono

Fonte: Disponível em: http://www.digifit.com/Zeo/ acesso em: 03/06/2014. 
> Certificação digital: é a tecnologia que viabiliza a utilização do meio eletrônico, garantindo confiabilidade, autenticidade, sigilo e legalidade às transações. É o serviço referente à solução de prontuário eletrônico do paciente (PEP). Os dados históricos do paciente ficam armazenados e podem ser acessados via internet. Uma das inovações é que o certificado digital é a chave privativa do médico que possibilita ao profissional assinar digitalmente o prontuário eletrônico do paciente - PEP. A interoperabilidade entre os sistemas e a adaptação às certificações digitais para uso administrativo e assistencial tornam-se recomendadas uma vez que entidades de qualidade como Organização Nacional de Acreditação - ONA e a Joint Comission que exigem uma gestão apurada em seus processos.

Sistema de imagem digital: além de dispensar os filmes fotográficos, uma das primeiras aplicações desenvolvidas foi a reconstrução tridimensional (3D) de determinadas partes do organismo. Usando técnicas especiais de software, obtém-se uma imagem realista, com sombreamento e perspectiva, que pode ser girada dinamicamente em várias direções, dando a sensação espacial desejada. Outra vantagem é a obtenção e o processamento das chamadas imagens funcionais. A velha radiografia de Raio $X$ mostra imagens essencialmente anatômicas. Conseguiu-se desenvolver sistemas capazes de mostrar em grande detalhe e de forma dinâmica o metabolismo celular, a distribuição e movimentação de substâncias endógenas, o fluxo sanguíneo, a síntese celular e muitas outras coisas.

Os dois procedimentos diagnósticos mais relevantes nessa área são atualmente o Positron Emission Tomography - PET e a Ressonância Magnética Funcional (fMRI). Ambos são capazes de mapear, com impressionante precisão, o local de uma alteração funcional, bem com quantificá-la. Atualmente há sistemas comerciais que combinam imagens de várias modalidades, de modo a obter o melhor de cada uma.

Talvez o maior benefício de trabalhar apenas com imagens médicas digitais é que, através de uma rede própria do hospital, interligada por cabos ópticos de alta velocidade, é possível montar uma Intranet de alto desempenho, o chamado Picture Archiving and Communication, ou, Sistemas de Arquivamento e Comunicação de Imagens - PACS. Assim, o médico pode visualizar o resultado do exame da imagem sem necessidade de revelação do filme, instantaneamente, em qualquer ponto do hospital.
Uma tendência mais recente permite também disponibilizar as imagens na Web para serem visitadas pelos médicos em qualquer lugar do mundo. Um dos principais responsáveis pela grande difusão da radiologia digital e dos PACS foi a adoção de padrões mundiais de comunicação digital para imagens médicas, como o Digital Imaging and Communication in Medicine - DICOM.

A internet na saúde: o volume e variedade de informações disponíveis no ambiente internet sobre assuntos relacionados à medicina e à saúde são inúmeros e não param de crescer. A internet oferece não apenas os tipos de informação médica presentes nos meios tradicionais impressos, mas também outros meios digitais, como gravações de áudio e vídeo, desenhos animados, imagens e textos interativos. A internet possui recursos de informação e interação de relativamente fácil usabilidade e acesso, e introduz mudanças importantes na educação, pesquisa e assistência, que passou a ser indispensável para os "modernos" profissionais da área da saúde. Os pacientes podem ter acesso de forma mais ágil as mesmas fontes de informação primária e secundária de seus médicos, dentistas, laboratórios, entre outros serviços.

A internet e o acesso em banda larga acabaram com a necessidade dos médicos de estarem em seus consultórios para acessar os dados dos pacientes, facilitando a consulta e o acompanhamento domiciliar. Por outro lado, ao contrário de outros setores, nos quais a tecnologia geralmente é atualizada, no segmento da saúde ela é agregada. Ou seja, a adoção de um novo método ou equipamento não necessariamente elimina os antigos. A consequência disso é um processo contínuo de "encarecimento" dos serviços. Para reverter o quadro, nada melhor que oferecer ao cliente serviços que correspondam exatamente às suas necessidades, deixando os grandes hospitais livres para os procedimentos mais urgentes ou complexos. A informática e as telecomunicações estão unidas para o desenvolvimento tecnológico e social do setor da saúde. A promessa da telemedicina, que possibilita desde o tratamento e acompanhamento médico até a educação a distância $(\mathrm{EaD})$ de pacientes e de profissionais, reflete na redução de custos operacionais e eficiência no atendimento em hospitais, clínicas e planos da saúde.

Para Dias et al. (2013) o impacto proporcionado pelo surgimento da internet gerou repercussões em todos os aspectos da sociedade. Da mesma forma, os autores salientam que os hospitais têm estado a cada dia mais envolvidos nessa nova realidade, em que a modernização da comunicação como ferramenta de relacionamento para seus 
diferentes públicos se tornou crucial. Assim, as organizações da área da saúde têm disponibilizado em seus portais na web uma ampliação da oferta de serviços e produtos, proporcionando novas funcionalidades no processo de comunicação, sendo que para os hospitais no sentido de facilitar o planejamento, reduzir os gastos, melhorar o gerenciamento, além de facilitar o acesso das pessoas as instituições da saúde.

Telemedicina: Segundo a Resolução do Conselho Federal de Medicina $\mathrm{n}^{\circ} .1 .643 / 2002$ Art. $1^{\circ}$ : a telemedicina é o exercício da Medicina através da utilização de metodologias interativas de comunicação audio-visual e de dados, com o objetivo de assistência, educação e pesquisa em Saúde. Entende-se que é qualquer tipo de aplicação da área médica que utiliza uma infra-estrutura de telecomunicação para transmissão de dados. A telemedicina permite a realização de ações médicas à distância.

As informações são utilizadas basicamente para medidas assistencialistas e preventivas, que vão desde um simples esclarecimento de dúvidas pelo telefone até o atendimento médico em um local com poucos recursos, em que a segunda opinião de um especialista por videoconferência representa um diferencial. Para os hospitais, o uso da telemedicina pode acarretar na redução dos custos operacionais e no aumento da eficiência e rapidez dos diagnósticos, pois, com a digitalização dos exames, por exemplo, o médico pode ter acesso, pela web, às imagens traçando rapidamente o diagnóstico.

A telemedicina permite a realização de ações médicas à distância. Uma de suas aplicações mais frequentes são nas Unidades de Atenção Primária à Saúde, onde buscam outras instituições médicas de referência para uma segunda opinião médica, consultorias e trocas de informações. Outras aplicações da telemedicina são: discussões de casos clínicos, auxílio diagnóstico, assistência a pacientes crônicos, idosos e gestantes de alto risco, assim como na assistência direta ao paciente em sua casa, através da visita domiciliar realizada pelo médico do programa saúde da família.

No Brasil, as ações em telemedicina vêm sendo realizadas desde a década de 90 , porém de maneira tímida. Um país com dimensões continentais, no entanto, tem muito a ganhar com a formação e a consolidação de redes colaborativas integradas de assistência médica a distância. Benefícios como a redução dos custos com transportes e comunicações e a possibilidade de levar a medicina especializada a regiões remotas do país torna-se um grande diferencial.

\begin{abstract}
TISS (Troca de Informação em Saúde Suplementar) e TUSS (Terminologia Unificada da Saúde Suplementar): em virtude da complexidade presente dentro ambientes da área da saúde, quando nos referimos a troca de informações entre as operadoras de planos de assistência à saúde e prestadores de serviços da área o projeto da Agência Nacional da saúde Suplementar (ANS) representou a integração entre operadoras e prestadores de serviços, o que deve impulsionar a informatização da área. Esse foi um importante passo para criar a cultura de informatização dentro dos hospitais. Sendo assim, a Agência Nacional da saúde Suplementar publicou no dia 13 de novembro de 2009 a Instrução Normativa $\mathrm{n}^{\circ}$ 38, que determina que as operadoras de plano privado de assistência à saúde e prestadores de serviços da saúde deverão obrigatoriamente adotar a TUSS para codificação de procedimentos médicos.
\end{abstract}

> Redes sociais: as ferramentas de microblog incluem na web novos públicos e geram oportunidades para as áreas de marketing institucional na área da saúde. Muitas organizações procuram estabelecer relacionamentos nas redes sociais como um tipo de tendência de mercado. A área da saúde ganha ao estabelecer com seu potencial cliente visando alcançar seus interesses, com dados de medicina preventiva, orientações e eventos.

O contato com o público possibilita informações mais rápidas, por meio de posts, além da possibilidade de jornalistas estarem acompanhando. Entretanto, as redes sociais demandam investimentos e a aproximação de profissionais da saúde, cientistas, instituições e até ex-pacientes - portanto, as redes sociais podem ser percebidas como um ativo intangível valioso para as organizações. Os hospitais definem políticas de uso das redes sociais com base em regras básicas de conduta, isto se aplica aos médicos, funcionários, voluntários, colaboradores e terceiros. A criação de canais nas redes sociais para áreas específicas dos hospitais pode ser feita pelo Twitter, Facebook, YouTube, Flickr, Formspring, SoundCloud, SlideShare, entre outros, porém deve ser realizada com o apoio de profissionais de mídias digitais.

Miller e Tucker (2013) observaram as postagens que os funcionários e clientes de um hospital realizaram com o canal de redes sociais. Os resultados conduziram a entender de forma mais clara as políticas de mídia social para que não ocorram distorções de informações no incentivo do uso destas ferramentas. Uma das iniciativas de destaque do 
Ministério da Saúde foi a campanha de incentivo à doação de órgãos, lançada em julho de 2012, no Facebook (BLOG DA SAÚDE ${ }^{5}, 2012$ ). Portanto, as redes sociais têm sido utilizadas como parte dos esforços de comunicação em saúde pública.

> Os robôs a serviço da medicina: o excesso de fascinação combinado com alta tecnologia transformou o impensável em realidade. Robôs mecânicos de alta precisão invadiram os ambientes hospitalares, aliados aos recursos de áudio, vídeo, e inúmeros sensores, para auxiliar os profissionais da saúde nos processos existentes dentro de um hospital. Os pacientes com problemas cardíacos, cerebrais e urológicos são tratados com ajuda de braços robóticos, que levam câmeras e instrumentos para dentro do corpo humano, e permitem maior controle e precisão dos instrumentos cirúrgicos, com procedimentos minimamente invasivos. A seguir, destacam-se algumas inovações que prometem auxiliar e facilitar o serviços relacionados à saúde com o uso de robôs:

Robô cientista: denomidado Adam, o robô prepara experimentos, monitora seu desenvolvimento e analisa os resultados obtidos. Em atuação desde 2008, já identificou funções para genes até então desconhecidos (Figura 02).

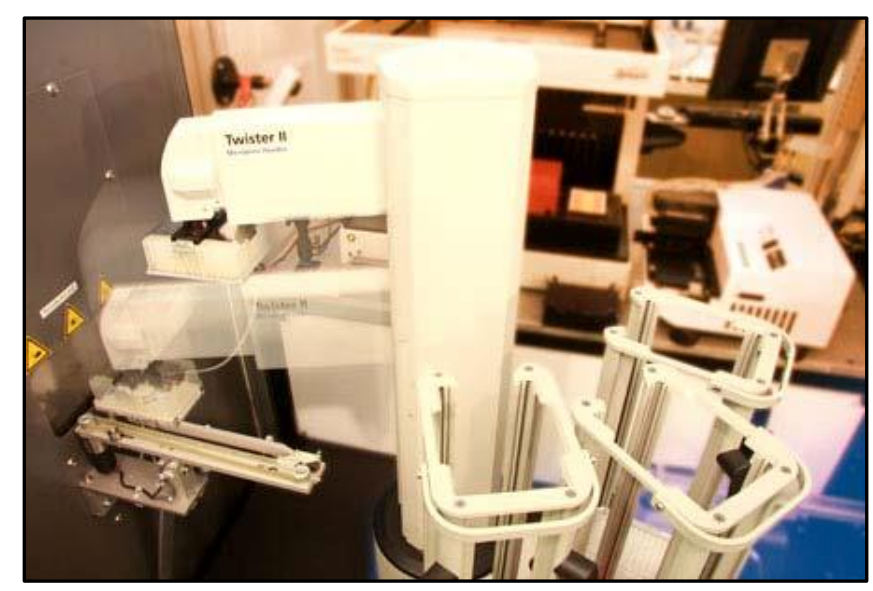

Figura 2 - Adam, o Robô Cientista

Fonte: Disponível em: http://cienciahoje.uol.com.br/noticias/2011/03/robos-cientistas/?searchterm=robótica Acesso em: 03/06/2014.

Robô à serviço da telemedicina: a fabricante americana de robôs para telemedicina VGo, em uma de suas últimas inovações criou um robô capaz de ajudar doentes e pacientes incapacitados a comparecer em salas remotamente, além de permitir a médicos especialistas "visitarem" pacientes em hospitais rurais e clínicas sem a necessidade de viajar e permitindo o atendimento virtual em casas. Isto ocorre por meio de uma combinação de videoconferência e tecnologia robótica, que permite o movimento e a interação com os pacientes e a equipe médica. $O$ robô é controlado remotamente pela pessoa que está interagindo por meio dele. O VGo, nome dado pela empresa (vide imagem), pode "ver, ouvir e falar" por meio da câmera e quatro microfones que são os "ouvidos" e "olhos" da pessoa que o está controlando, possui também um alto-falante que age como a voz da pessoa, que controla os movimentos do robô usando um mouse e a tela do computador. Dentre seus aplicativos de telemedicina estão: treinamento médico, reabilitação, serviços de intérprete, hospitalizações a longo prazo, rondas hospitalares para médicos que estejam no consultório ou em casa e segundas opiniões médicas. Os robôs VGo podem ser usados por organizações da saúde, hospitais infantis e clínicas visando o aumento da eficiência da equipe médica (Figura 03).

\footnotetext{
${ }^{5}$ Disponível em: http://www.blog.saude.gov.br Acesso: 03/06/2014.
} 


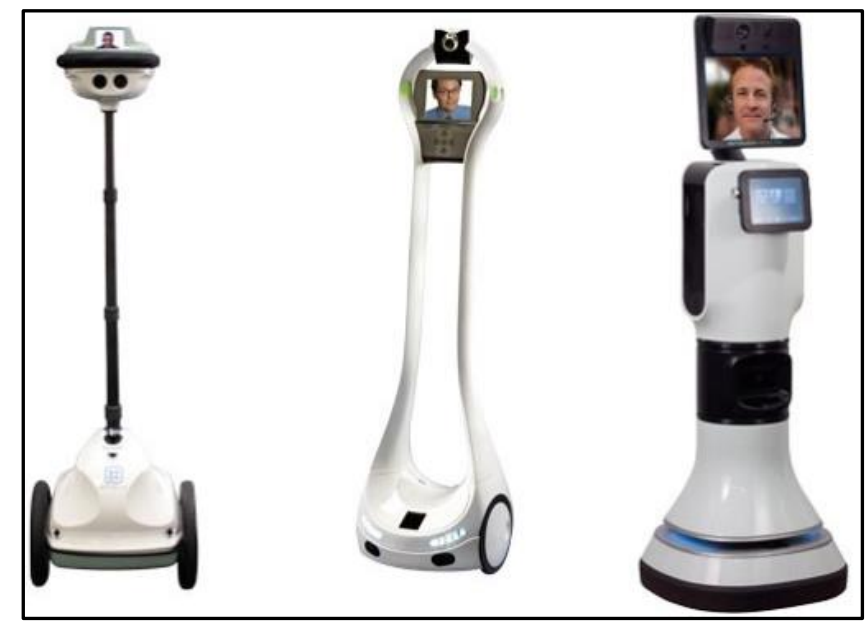

Figura 3 - Mobilidade e praticidade na Telemedicina

Fonte: Disponível em: http://forbesbrasil.br.msn.com/fotos/o-sucesso-dos-robôs-de-telepresença?page=8\#image=1

Acesso em: 03/06/2014.

> Mobilidade: outra inovação tecnológica promissora é o robô QC Bot que visa enfrentar os desafios logísticos em ambientes da saúde e melhorar o cuidado do pacientes. Trata-se de uma plataforma robótica é multifuncional, que permite inúmeras atividades, desde o monitoramento de segurança, entrega da farmácia, remoção de resíduos e a entrega de refeições. O equipamento tem inteligência artificial e um sistema de envio de programação que permite que ele navegue de forma autônoma em instalações da saúde. Possibilita o rastreamento e a documentação do fluxo logístico de trabalho usando a tela de toque do robô e seu software associado. Para o paciente, essa mesma tela de toque facilita serviços como auto check-in, localização, registro e telepresença clínica. Ele também pode se conectar com o software de vigilância de infecções da empresa para fornecer atualização em tempo real para gerenciamento e prevenção de infecções associadas ao cuidado (Figura 04).

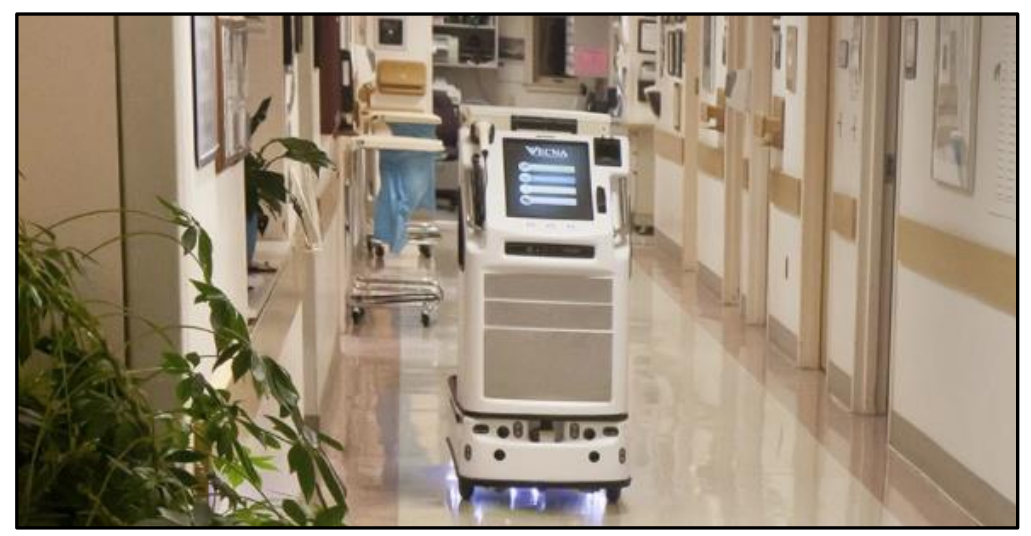

Figura 4 - Superando desafios logísticos

Fonte: Vecna Technologies is developing an autonomous telepresence, patient self-service, and product delivery robot for hospitals. Produced by Erin Baldassari for the Boston Phoenix. Disponível em: http://www.vecna.com Acesso em: 03/06/2014. 
> Método de localização de pessoal hospitalar mediante Sistema de Rastreamento de ativos - Tecnologias RFID - Radio Frequency Identification: o Sistema de Rastreamento de ativos é um método de identificação automática através de sinais de rádio, que recupera e armazena dados remotamente através de dispositivos denominados etiquetas RFID, que é um pequeno objeto que pode ser colocado em pessoas e objetos, que contém chips que respondem aos sinais de rádio enviados por uma base transmissora. Este método é utilizado dentro dos ambientes hospitalares e permite monitorar as condições dos pacientes e de equipamentos no complexo hospitalar, identificando e localizando a qualquer momento o usuário / equipamento. A identificação por radiofrequência pode contribuir para a melhoria nos processos na assistência. Esta tecnologia poderia ser usada também para monitoriamento dos pacientes com a integração do sistema de controle de sinais vitais e uso de etiquetas inteligentes RFID, dessa maneira, o controle passa a ser operado em tempo real para o rastreamento físico, e na gestão de suprimentos da instituição.

$>$ Combinação de luz com tecnologias de LED: os pesquisadores de plantão desenvolvem a cada dia produtos voltados a iluminação que combinados com tecnologias inovadoras, contribuem para surgimento de novas tendências no mercado, principamente quando se trata da área da saúde. Ou seja, além de iluminar o ambiente, os LED estarão simultaneamente transmitindo os dados da sua conexão com a internet, com alta velocidade e com segurança. Testes já estão sendo realizados para a implantação da tecnologia em hospitais.

\subsection{Ultrapassando Barreiras}

A seguir serão apresentados alguns exemplos de estudos e tecnologias que estão em fase de teste, frente a necessidade do mercado, que supera as expectativas e gera a diferença competitiva entre os empresários do ramo, este fator já está sendo determinante no mercado cujo resultado são diversas pesquisas e inovações neste setor (Siqueira, 2007).

$>$ Touch Screen: a famosa tecnologia (também conhecida como tela sensível ao toque), que dispensa o uso de equipamentos como teclados e mouses, cujo uso é comum em telefones celulares, videogames portáteis, caixas eletrônicos, quiosques multimídia, entre outros, se mostra cada vez mais presente em hospitais e em equipamentos relacionados à saúde, cientistas do Instituto Avançado de Ciência e Tecnologia da Coreia, estudam possibilidades da tecnologia detectar doenças com a capacidade de reconhecer a existência e a concentração de moléculas de DNA localizadas neles, um primeiro passo para um dia sermos capazes de usar as telas para carregar nossos exames médicos. A tecnologia também é utilizada em tablets e smartphones, presente em eletrocardiogramas, dentre outros equipamentos que aliadas à programas específicos, como leitor de RFID e reconhecimento biométrico, auxiliam nos diagnósitcos médicos.

> Impressão em 3D: aliada ao sistema de imagem digital, a impressão em 3D já está no mercado há algum tempo, mas é aplicada na medicina, como por exemplo, para escanear o restante da perna de um paciente que teve o membro amputado. Deste modo, a construção de uma prótese com o tamanho correspondente poderá ser possível, devido ao fato da impressão ter a integração rápida com o desenvolvimento das células tronco e medicina regenerativa, com a tinta 3D sendo substituída por células tronco. Sendo assim, cientistas afirmam que no futuro é provável que a impressão 3D e células tronco sejam utilizadas na criação de arquivos e peças de reposição.

> Robôs de alta precisão: desde 2007 a empresa japonesa Toyota está desenvolvendo robôs exclusivos para a área da saúde, com a previsão de lançamento dos equipamentos para o ano de 2013. A empresa dispõe de aparelhos que proporcionam a liberdade de movimentos e dão independência para as pessoas incapacitadas por doença ou lesão e, ao mesmo tempo, ajudam em sua recuperação. Os equipamentos possuem motores de alta precisão, controle de estabilidade em duas pernas, sensor de correção de postura e sistemas para pegar e segurar objetos. Além disso, há robôs que auxiliam no carregamento e movimentação de componentes pesados em fábricas e que permitem o funcionamento autônomo de ferramentas. São quatro os aparelhos destinados à área da saúde apresentados pela Toyota, sendo eles: 
Perna Robótica Independente: visa auxiliar as pessoas cuja capacidade de andar foi prejudicada por paralisia. Montado no local paralisado, o robô flexiona o joelho para facilitar a caminhada natura (Figura 05).

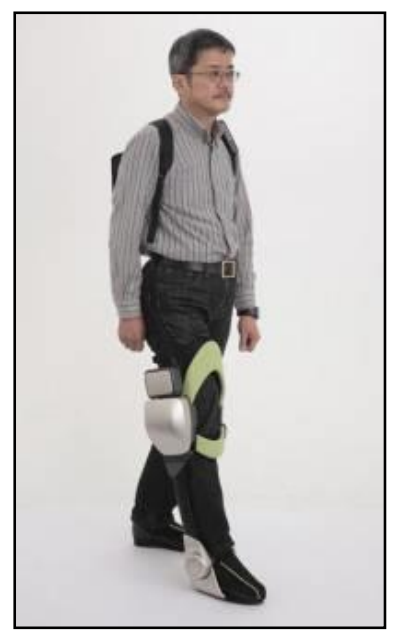

Figura 5 - Perna Robótica

Fonte: Disponível em: http://www.toyotaimprensa.com.br/releases/release.php?id=3047 Acesso em: 03/06/2014.

Andador robótico: auxilia o caminhar natural para pessoas cuja movimentação das pernas foi comprometida (Figura 06).

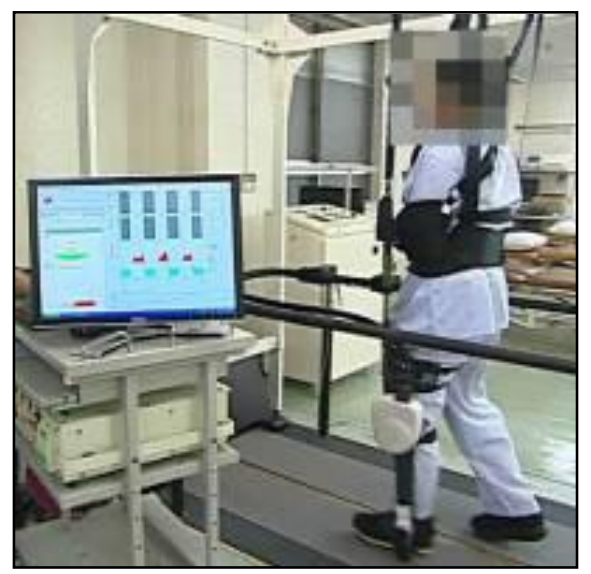

Figura 6 - Andador robótico

Fonte: Disponível em: http://www.toyotaimprensa.com.br/releases/release.php?id=3047 Acesso em: 03/06/2014.

Assistente de Recuperação de Equilíbrio: o aparelho funciona como um pêndulo para buscar a reeducação do equilíbrio natural do corpo (Figura 07). 


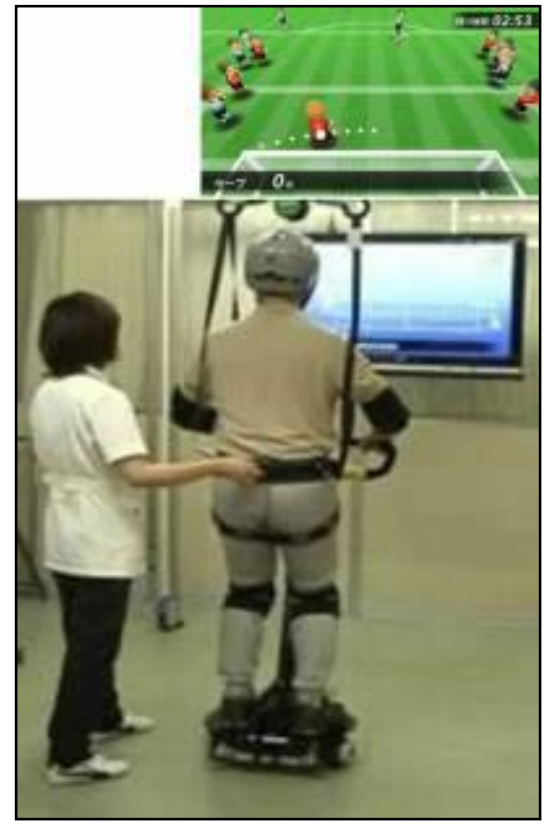

Figura 7 - Assistente de recuperação de equilíbrio

Fonte: Disponível em: http://www.toyotaimprensa.com.br/releases/release.php?id=3047 Acesso em: 03/06/2014.

Assistente de Transferência de Pacientes: desenvolvido para reduzir o esforço físico exigido dos profissionais de enfermagem na transferência e mobilidade de pacientes (Figura 08).

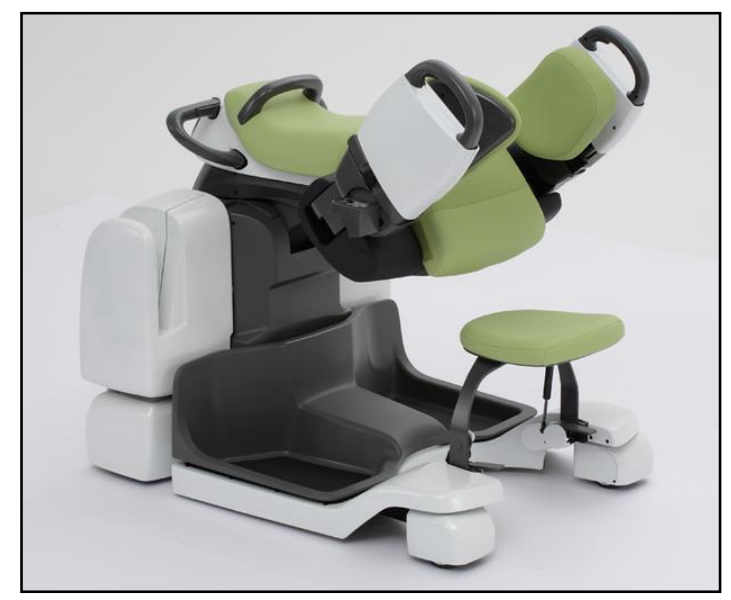

Figura 8 - Assistente de transferência de pacientes

Fonte: Disponível em: http://www.toyotaimprensa.com.br/releases/release.php?id=3047 Acesso em: 03/06/2014.

\subsection{Hospital HighTech}

O El Camino Hospital ${ }^{6}$ - The Hospital of Silicon Valley no estado da Califórnia, Estados
Unidos, é um bom exemplo do uso de alta tecnologia, pois é considerado um dos hospitais mais modernos do mundo. Há vários tipos de TICs incorporadas em seus serviços, entre elas: a robótica (auxiliando nas

\footnotetext{
${ }^{6}$ Disponível em: http://www.elcaminohospital.org. Acesso em: 03/06/2014.
} 
cirurgias, principalmente, nas que exigem maior precisão como é o caso do Robô Cirúrgico - Da Vinci; separando na farmácia os medicamentos a partir da prescrição médica; entrega de materiais hospitalares

\section{Figura 9 - Robô Cirúrgico - Da Vinci}

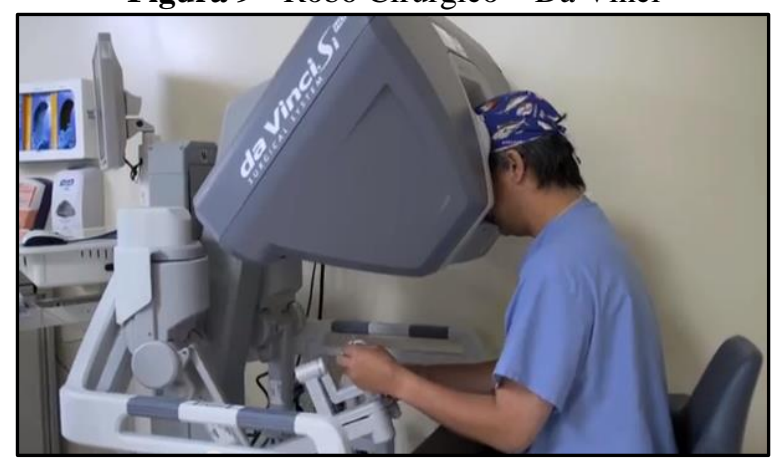

Fonte: El Camino Hospital. para os diferentes setores); photon terapia; registro biométrico - Palm Secure; o Robô Radio-Cirúrgico Cyber Knife e o Sistema de Comunicação Móvel de Voz - Vocera.

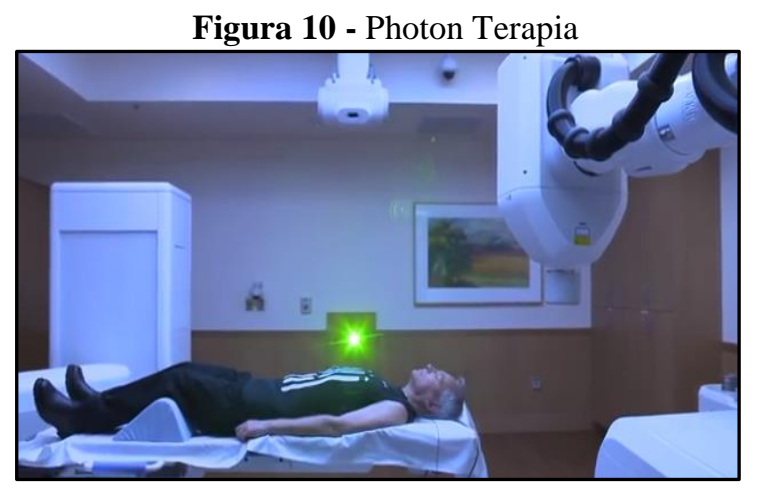

Fonte: El Camino Hospital.

atendimento aos pacientes, aumentava substancialmente o custo do atendimento.

O modelo de negócio da saúde brasileira ainda é muito complexo porque além dos universos com uma visão macro (saúde pública, suplementar, e complementar), o cenário ainda tem vários nichos de mercado diferentes como hospitais que pertencem às operadoras da saúde, cooperativas médicas, medicina de grupo, entre outros. Essa diversidade obriga cada organização estabelecer processos diferentes que refletem em soluções diferentes. Entretanto, a padronização pode ser considerada uma questão de sobrevivência para proporcionar a continuidade do modelo de negócio da área da saúde e o setor já sabe disso e busca esses padrões, principalmente, para a comunicação e troca de informações.

O padrão também é importante no avanço de práticas de gestão como o uso do prontuário eletrônico porque o histórico médico como propriedade de cada pessoa deve ser hospedado e gerenciado por cada instituição num padrão que seja acessado por todos e, principalmente, pelo paciente. Portanto, o prontuário eletrônico representa o acesso à informação e, a partir disso, a área da saúde como um todo tem mais capacidade de reduzir custos e desperdícios, além de garantir a vida.

Nesse sentido, aliada as diretrizes e regulamentações que cada país possui é fundamental a importância que é dada para a segurança das informações, no momento do compartilhamento e uso. Os benefícios são inúmeros, porém, é fundamental que não ocorra vazamento de informações, como podem ocorrer em blogs e portais que discutem casos clínicos. Diante disso, para evitar qualquer tipo de problema, como o vazamento de informações ou exposição desnecessária das entidades, os hospitais devem se prevenir tomando providências, entre as principais observadas pelas TICs apresentadas neste estudo são: 
não associar conteúdo pessoal ou de opinião pessoal as atividades profissionais; não publicar informações de rotinas de trabalho; não publicar informações confidenciais; e não praticar ofensas a outros membros da instituição.

Contudo, para Drucker (2002) o hospital é a organização humana mais complexa já concebida, além de ser um dos tipos de organização de maior crescimento. O hospital também é considerado uma organização complexa, uma vez que detém uma multiplicidade de profissionais, de procedimentos de risco e processos críticos, somada a incorporação de novas TICs, processos e práticas de gestão. Como o hospital é uma das organizações mais complexas operadas pelo homem torna-se imperativo ter um instrumento que permita disponibilizar mais rapidamente os dados a respeito do seu funcionamento, de maneira a estruturar a gestão de forma sistemática. Este grande desafio, se bem enfrentado, trará resultados palpáveis para a gestão, independente de qual seja a variável, Tecnologia da Informação e Comunicação (TIC), Prontuário Eletrônico do Paciente (PEP), Business Intelligence (BI), a gerência pode ser ajudada por um conhecimento melhor e mais oportuno dos dados do funcionamento dos hospitais.

Entre as principais conclusões deste estudo pode-se destacar a criticidade e a importância da segurança e da qualidade dos cuidados assistenciais aos pacientes. $\mathrm{O}$ uso da internet como ferramenta de comunicação torna-se um importante fator estratégico de gestão nas organizações da saúde. Dentre as vantagens, facilita na segmentação dos clientes; aceitação por diferentes públicos; permite comparar resultados em tempo real; ampla cobertura; anúnicos e notícias em tempo real; além de apresentar maiores resultados de informações em relação aos meios de comunicações convencionais.

Em relação ao escopo do estudo e suas limitações fica claro que foram apresentadas algumas das principais TICs em saúde que estão sendo utilizadas no Brasil, e algumas internacionais que possuem condições de serem adotadas no país dada a flexibilização e da internacionalização da saúde, principalmente, para atender os quesitos de certificações de qualidade internacionais. Assim, a tecnologia pode agir como legitimadora do ato profissional da saúde e da instituição que a adota, sendo utilizada como critério de avaliação de qualidade dos seus serviços prestados.

Existe ainda, uma vinculação entre os interesses capitalistas no setor da saúde e a incorporação tecnológica no processo de produção dos serviços. Os avanços tecnológicos são fatores básicos da dinâmica do setor da saúde, com repercussões na organização dos serviços hospitalares, ambulatoriais e na prática médica, sendo possível observar, a expansão do setor industrial e a importação de tecnologias para suprir a demanda do país.

O conjunto de ferramentas de TICs na saúde dentro de seu escopo organizacional (estratégico, tático e operacional) indica que a escolha e a adoção de tecnologias não é algo isolado, pois existem variáveis de decisão, entre elas: políticas, econômicas e sociais, que trazem consigo muitas oportunidades e também desafios em função da renovação de valores humanos, necessidade de mudança cultural, e quebra de paradigmas.

Portanto, as TICs na saúde devem passar por uma postura crítica e reflexiva em sua adoção e incoporação, pois necessitam de uma avaliação sob o ponto de vista ético, administrativo (análise de viabilidade financeira), assistencial (qualidade na atenção), dos benefícios, limitações, e dos riscos que uma tecnologia mal planejada e adotada pode trazer para a sociedade.

\section{REFERÊNCIAS}

Abrahão, Marivan S. (2003) A segurança da informação digital na saúde.

Alba, Milena. (2012) Inovações Tecnológicas na Área da Saúde, http://saudeweb.com.br/galeria/12inovacoes-tecnologicas-na-area-da-saude/Último acesso em: 10/01/2012.

Andrade, Maria Aparecida de. Introdução à metodologia do trabalho científico. 5.ed. São Paulo: Atlas, 2001.

Audy, Rejane Blomberg.; Caye, Lúcia. (2013) Tecnologia Móvel na Instituição. QUALIHOSP 2013, Protocolo n. 87, Gestão da Assistência.

Barra, D. C. C.; Nascimento, E. R. P.; Martins, J. J.; Albuquerque, G. L.; Erdmann, A. L. (2006) Evolução histórica e impacto da tecnologia na área da saúde e da enfermagem. Revista Eletrônica de Enfermagem, v. 08, n. 03, p. 422-430.

Barros, Jacson.; Silva, Gisele Regina Pereira da.; Santos, Paula V dos.; Reis, Mariluz dos. (2013) Modelo de gestão do fluxo de regulação de pacientes com o uso de ferramentas de Business Process Management (BPM). QUALIHOSP 2013, trabalho n. 124, Gestão das Redes de Atenção à Saúde.

Borges, Mônica E. N. (1995) A informação como recurso gerencial das organizações na sociedade do conhecimento.

Campos, Edna.; Teixeira, Francisco Lima. (2004) Adotando a Tecnologia da Informação: análise da 
implementação de sistemas de "Groupware". RAE-eletrônica, v. 3, n. 1, Art. 2, jan./jun.

Cassiani, Silvia Helena de Bortoli et al. (2005) O sistema de medicação nos hospitais e sua avaliação de um grupo de profissionais. Revista da Escola de Enfermagem da USP, São Paulo, v. 39, n. 3, p. 280287 , set.

Cervo, Amado L.; Bervian, Pedro A. (2006) Metodologia científica. 5.ed. São Paulo: Pearson Prentice Hall.

Chiasson, M. W.; Davidson, E. (2004) Pushing the contextual envelope: developing and diffusing IS theory for health information systems research. Information and Organization, v. 14, p. 155-188.

Dias, L. P. M.; Monticelli, M.; Reibnitz, K. S.; Lima, L. M. (1996) Possibilidade de conhecimento e arte na produção de inventos de enfermagem. Revista Texto \& Contexto Enfermagem. V. 5, n. 1, p. $92-$ 110.

Dias, Wellington da Silva.; Cruz, Daniela Imolesi.; Porta, Marcela Rodrigues de Souza.; Paulo, Renta Rodrigues Daher.; Gandolfi, Peterson Elizandro.; e Martins, Vidigal Fernandes. (2013) O uso das mídias digitais como estratégia de comunicação em hospitais universitários de grande porte. QUALIHOSP 2013, Trabalho n. 15, Comunicação em Saúde.

Drucker, Peter. (2002) Managing in the Next Society. Editora: Butterworth Heinemann.

Gadelha, Carlos Augusto Grabois. (2003) O complexo industrial na saúde e a necesside de um enfoque dinâmico na economia da saúde. Ciência \& Saúde Coletiva, Rio de Janeiro, v. 8, n. 2, p. 521535.

Gadelha, Carlos Augusto Grabois. (2006) Desenvolvimento, complexo industrial da saúde e política industrial. Revista da saúde Pública, 40 (N Esp), p. 11-23.

Gil, Antônio Carlos. (2010). Como Elaborar Projetos de Pesquisa. São Paulo. Editora Atlas, $5^{\text {a }}$ edição, $184 \mathrm{p}$.

Hannan, Kathryn J., BALL J. Marion, EDWARS, J. A. Margaret. (2009) Introdução à informática em enfermagem. $3^{a}$ Edição, Porto Alegre: Artmed.

Laurindo, F. J. B. (2002) Tecnologia da informação. São Paulo: Futura.
Mañas, Antonio Vico. (2002) Administração de Sistemas de Informação: Como Otimizar a Empresa por Meio dos Sistemas de Informação. São Paulo. Editora Érica, $3^{a}$ Edição, 285 p.

Marcovitch. J. org. (1996) Tecnologia da informação e estratégia empresarial. $1^{a}$ ed. São Paulo: Futura. $130 \mathrm{p}$.

Miller, Amalia R.; Tucker, Catherine. (2013) Active Social Media Management: The Case of Health Care. Information Systems Research. Volume 24 Issue 1, March, p. 52-70.

Moura, Luciano Raizer. (1999) Gestão Integrada da Informação: proposição de um modelo de organização baseado no uso da informação como recurso da gestão empresarial. Dissertação de Mestrado. São Paulo: EPUSP.

Oliveira, Macir Bernardo de.; Spinola, Mauro de Mesquita. (2005) A Influência da Tecnologia da Informação nas Estratégias de Negócios do Setor da Saúde. XI Seminário Latino-Iberoamericano de Gestión Tecnológica. Salvador - Bahia, Brasil. Altec.

Oliveira, Djalma de Pinho Rebouças de. (1995) Excelência na administração estratégica - a competitividade para administrar o futuro das empresas. São Paulo: Atlas.

Pinto, Virgínia Bentes. (2006) Prontuário eletrônico do paciente: documento técnico de informação e comunicação do dominio da saúde.

Porter, Michael E. (1991) Estratégia competitiva: técnicas para análise de indústria e da concorrência. Rio de Janeiro: Campus.

Raitoharju, R.; Laine, M. (2006) Exploring the differences in information technology acceptance between healthcare professionals. In: American Conference on Information Systems, 12., Mexico. Proceedings... Mexico, 2006. p. 2644-2651.

Roberts, K.; Grabowsky, M. (1996) Organizations, technology and structing. Em Clegg, S. Hardy, C \& Nord, W. (orgs.), Handbook of organization studies. Londres: Sege Publications.

Rodrigues, Raquel M.; Andreazzi, Maria de Fátima S. (2011) Desafios da incorporação tecnológica em sistemas locais da saúde.

Sabbatini, Renato M. E. Informática médica, http://www.sabbatini.com/renato/papers/checkup10.htm. Último Acesso em: 20/08/2011. 
Sabbatini, Renato M. E. Informática médica, http://www.informaticamedica.org.br/informed/eti ca.htm. Último Acesso em: 21/12/2011.

Santos, J. F.; Vieira, M. M. F. (1998) Mudança tecnológica e mecanismos de coordenação: A introdução da informática em uma empresa de construção civil. Anais do $22^{\circ}$ EnANPAD Encontro Nacional dos Programas de PósGraduação em Administração.

Santos, Antônio C. P. (1998) Análise Setorial: Sistema Hospitalar. São Paulo: Gazeta Mercantil.

Serafim, Sonia Aparecida Dias. (2005) Impacto da Informatização na Dispensação de Medicamentos em um Hospital Universitário. 99 p. Dissertação (Mestrado em Saúde na Comunidade) - Faculdade de Medicina de Ribeirão Preto da Universidade de São Paulo, Ribeirão Preto.

Siqueira, Ethevaldo. (2007) Tecnologias que mudam nossa vida. São Paulo: Saraiva.
Spinola, Mauro, PESSÔA, Marcelo. S.P. (1997) Tecnologia da informação. In: Gestão de Operações. São Paulo: Edgard Blucher.

Souza, Alexandre; Zwicker, Ronaldo. (2000) Implantação de sistemas ERP: um estudo de casos comparados. São Paulo, EnANPAD.

Sweeney, G.P. (1989) Information and corporate growth. London: VK: Pintes Publishers.

Tapscott, Don. (1998) Growing up digital: the rise of the net generation. McGraw Hill - NY.

Tenório, Fernando Guilherme. (2007) Tecnologia da informação transformando as organizações e o trabalho. Rio de Janeiro: Editora FGV.

Tupinambá, Regina. Certificação Digital, http://rtupinamba.blogspot.com/2011/05/novometodo-de-codificacao-protege.html. Último acesso em: 10/01/2012. 